\title{
PERANCANGAN PEMENUHAN PERMINTAAN PASOKAN GULA RAFINASI DENGAN METODE WAGNER WHITIN
}

\author{
Hendy Tannady \\ Program Studi Teknik Industri, Fakultas Teknologi \& Desain, Universitas Bunda Mulia \\ Jl. Lodan Raya No. 2, Ancol-Jakarta Utara \\ htannady@bundamulia.ac.id / hendytannady@yahoo.com
}

\begin{abstract}
Abstrak
Tidak bisa dipungkiri, setelah melewati tahapan dimana faktor Kualitas dan Kapabilitas Memproduksi Masal merupakan dimensi yang dianggap penting bagi industri dalam terus mempertahankan eksistensi dan mampu terus berkompetisi, kini kompetisi industri tengah memasuki era kompetisi dimana kapabilitas yang baik dalam Information Technology dan Supply Chain Management dipandang dapat menjadi bagian penting kompetensi pokok untuk terus bersaing. Penelitian ini membahas tentang perancangan pemenuhan permintaan terhadap permintaan gula rafinasi dari sebuah perusahaan yang berlokasi di Makassar, Sulawesi Selatan. Saat ini pemerintah memiliki kebijakan untuk membatasi jumlah perusahaan yang memiliki akses produksi dan menjual gula rafinasi, sedangkan pertumbuhan permintaan domestik terus tumbuh, mengantisipasi hal ini, diperlukan sebuah perencanaan terhadap strategi pemenuhan pesanan. Penelitian menggunakan metode Wagner Within dalam membantu perusahaan membuat rancangan persediaan. Tujuan jangka panjang adalah mencari metode terbaik yang dapat meringkas anggaran perusahaan tanpa mengesampingkan kepuasan customer. Menurut John dan Riley (1985) Supply Chain Management berhubungan dengan total aliran material dari supplier hingga customer akhir. Penelitian berfokus kepada aliran material dari Manufaktur kepada distributor dan manufaktur rekanan yang membutuhkan bahan baku untuk memproduksi produk lain. Data yang digunakan diambil menggunakan data riil sekunder, pengolahan data juga memasukkan variabel seperti biaya yang ditimbulkan akibat persediaan (Holding Cost) dan set up cost. Hasil akhir penelitian adalah diperoleh data tabel perencanaan persediaan untuk periode permintaan 12 periode kedepan untuk pemenuhan permintaan di area Makassar dan Manado, untuk area Makassar pemenuhan persediaan dilakukan setiap periode permintaan, sedangkan untuk area Manado pemenuhan persediaan dilakukan pada periode 1 dan 3 .
\end{abstract}

Kata Kunci : supply chain management, wagner within, perencanaan persediaan

\begin{abstract}
Inevitably, after passing through a stage where Quality and Mass Producing Capability factors is a dimension that important to considered for the industry to keep maintain its existence and able to compete, the competition of industry now entering the era of competition where a good capability in the Information Technology and Supply Chain Management become an important part of basic competence to continue to compete. This research discusses the design to fulfill demand for refined sugar demand from a company located in Makassar, South Sulawesi. The current government policy is to limit the number of companies that have access to the production and sells refined sugar, while the growth in domestic demand continues to grow, anticipating this, we need build a planning for order fulfillment strategy. This research using Wagner Within method in helping companies make the draft of inventory. The long term goal is to find the best method that can summarize the company's budget without compromising customer satisfaction. According to John and Riley (1985) Supply Chain Management related to the total flow of materials from the supplier to the end customer. The research focuses on the flow of material from manufacturing to distributors and manufacturing partners who need raw materials to produce other products. The data used were taken using secondary real data, data processing also include variables such as the cost incurred due to inventory (Holding Cost) and set up cost. The result of this research are obtained inventory planning table data for 12 periods future demand for meet demand in Makassar and Manado, in Makassar case, inventory fulfillment requests made in each period, while inventory fulfillment for Manado area done in periods 1 and 3.
\end{abstract}

Keywords : supply chain management, wagner whitin, inventory planning 


\section{PENDAHULUAN}

Menurut Badan Standardisasi Nasional (BSN), Gula Rafinasi atau Gula Kristal Rafinasi adalah gula sukrosa yang diproduksi melalui tahapan proses pengolahan gula kristal mentah (GKM) yang meliputi : afinasi, remelting, klarifikasi, dekolorisasi, kristalisasi, fugalisasi, pengeringan, dan pengemasan ${ }^{4}$. Penggunaan gula rafinasi sebagai salah satu komoditas bahan baku industri di Indonesia sangatlah pesat pertumbuhannya, hal ini dipengaruhi oleh pola konsumsi berbagai komoditas pangan oleh penduduk Indonesia, pada tahun 2011 pemerintah harus sampai mengimpor 2,75 juta ton beras ${ }^{6}$, begitupun dengan konsumsi gula dalam negeri, Indonesia merupakan negara konsumen gula terbesar sesudah Amerika Latin, meskipun mampu memproduksi gula 2,31 juta ton bagi kepentingan konsumsi dalam negeri, namun Indonesia tetap harus mengimpor 108.889 ton raw sugar dan 143.479 ton gula kristal putih ${ }^{6}$. Kondisi ini menjadi indikator betapa kompleksnya kebutuhan dan ketersediaan gula bagi pasar dan industri nasional. Pada situasi seperti ini pertimbangan biaya pemenuhan pemesanan, kapabilitas produksi, dan faktor-faktor eksternal yang mampu mempengaruhi aktivitas supply chain seperti terganggunya transportasi akibat tingginya gelombang air laut, kemacetan jalan serta faktor-faktor internal seperti biaya simpan dan fluktuatifnya rata-rata biaya produksi tentu menjadi critical point bagi pelaku usaha. Kondisi perusahaan yang saat ini sedang mencari bentuk terbaik dan metode terbaik dalam merencanakan waktu dan jumlah produk dalam lot size tonase yang akan diproduksi untuk kemudian dikirimkan ke gudang guna didistribusikan menjadi latar belakang dari penelitian. Tujuan dari penelitian adalah membantu membuat rancangan penerimaan persediaan guna mencukupi stok bagi sebuah perusahaan yang beroperasi sebagai produsen gula rafinasi, dengan lokasi pabrik dan gudang di Makasar, aktivitas distribusi dikonsentrasikan kepada distributor lokal dan langsung kepada perusahaan manufaktur sebagai komoditas bahan baku. Produsen minuman soda dalam kaleng, J@TI Undip, Vol VIII, No 3, September 2013 biskuit, hingga kopi kemasan adalah contoh produsen makanan dan minuman yang membutuhkan suplai gula rafinasi, usaha kecil dan menengah seperti pabrik roti rumahan dan sub distributor mendapatkan suplai gula dari distributor yang membeli secara langsung dari perusahaan gula rafinasi. Penelitian menggunakan metode Wagner Whitin dalam menyusun periode penerimaan, dua jenis permintaan dalam dimensi kuantitas adalah statik dan dinamik, dengan metode yang dikembangkan Peterson dan Silver (1979) akan diketahui nilai koefisien yang merefleksikan sifat dari data (statik atau dinamik) ${ }^{3)}$. Di dalam bukunya (Axsater, 2002) menulis bahwa penyelesaian terhadap masalah permintaan dinamik dapat diselesaikan dengan metode WagnerWhitin, metode yang dicetuskan oleh Wagner dan Whitin pada tahun $1958{ }^{1)}$. Penggunaan dan tulisan mengenai metode tersebut tidak banyak dilakukan oleh peneliti, beberapa tulisan hasil penelitian yang membahas seperti dalam paper berjudul "Fuzzy Wagner Whitin Algorithm and an Application of Class I Supplies"yang ditulis Baltacioglu dkk. Dimana metode Wagner-Whitin digunakan untuk menentukan tingkat stok material dalam gudang makanan serta membuat kebijakan pendukungnya dengan menggunakan data dari Turkish Armed Forces ${ }^{2)}$. Penelitian lain dilakukan oleh Sadjadi dkk yang mencoba melakukan improvisasi terhadap aplikasi dari metode Wagner-Whitin, yakni dengan membandingkan aplikasinya dengan dua kasus berbeda, kasus pertama diasumsikan tidak terdapat backlogging serta inventory cost dan set up cost diasumsikan fixed, sementara kasus kedua terdapat backlogging serta inventory cost dan set up cost diasumsikan tidak fixed, dimana hasil penelitian mengindikasikan adanya linearitas antara waktu eksekusi dari metode yang diajukan dengan jumlah periode dalam horison perencanaan ${ }^{5)}$.

\section{METODOLOGI PENELITIAN}

Penelitian dimulai dengan mengidentifikasi permasalahan yang dimiliki oleh perusahaan dalam menentukan 
periode dan besaran penerimaan, yang artinya juga akan mempengaruhi periode order ke lantai produksi. Kemudian mengidentifikasi jenis data permintaan apakah bersifat statik atau dinamik, ada dua jenis permintaan yang datang, yakni industri pengolahan atau manufaktur minuman dan makanan, serta distributor besar nasional yang kemudian mendistribusikan ke sub distributor dan pengusaha UKM yang membutuhkan. Penelitian membatasi rancangan persediaan hanya pada datangnya permintaan yang tidak pasti atau fluktuatif atau memiliki sifat dinamik, dalam kasus yang dimiliki perusahaan, permintaan yang datang dari distributor memiliki sifat yang dinamik dan sering kali signifikan perubahannya dari periode ke periode, terdapat 4 area seperti Banjarmasin, Bitung, Samarinda, dan Makassar, dimana perusahaan menjual produknya kepada distributor, jumlah distributor pada setiap area tidak dijelaskan pada makalah, hanya konsentrasinya adalah jumlah dan periode datangnya persediaan pada gudang di masing-masing area.
Pembatasan area pada penelitian dilakukan hanya di Pulau Sulawesi (Makassar dan Manado), namun sebagai validasi adanya permintaan yang bersifat dinamik dari distributor, akan ditampilkan data pada Tabel 3 yang memperlihatkan keseluruhan sifat data permintaan dari seluruh area distributor. Durasi waktu penerimaan gula ke customer diestimasikan dapat didistribusikan pada periode yang sama, sehingga faktor delivery yang tentunya dapat dilakukan oleh produsen atau customer akan dianggap stabil diluar sistem. Beberapa variabel yang digunakan dalam pengolahan data adalah holding cost, set up cost, dan besar permintaan 12 periode kedepan. Nilai yang diasumsikan stabil adalah holding cost, dimana nilai set up cost berbeda pada setiap area. Data variabel adalah data sekunder, horison waktu rancangan adalah 12, dimana 1 bulan didefinisikan sebagai 1 periode. Metode yang digunakan dalam menentukan periode dan besar persediaan adalah menggunakan metode Wagner-Whitin.

\section{HASIL DAN PERANCANGAN}

Tabel 1 Data Permintaan Gula Rafinasi Area Makassar

\begin{tabular}{crr}
\hline Periode & $\begin{array}{c}\text { Demand } \\
\text { Makassar (Ton) }\end{array}$ & \multicolumn{1}{c}{$\mathbf{D}^{\mathbf{2}}$} \\
\hline 1 & 7800 & 60840000 \\
2 & 3500 & 12250000 \\
3 & 6500 & 42250000 \\
4 & 2100 & 4410000 \\
5 & 6800 & 46240000 \\
6 & 11500 & 132250000 \\
7 & 2200 & 4840000 \\
8 & 7000 & 49000000 \\
9 & 3500 & 12250000 \\
10 & 9200 & 84640000 \\
11 & 8500 & 72250000 \\
12 & 2500 & 6250000 \\
\hline
\end{tabular}

Tabel 2 Data Permintaan Gula Rafinasi Area Manado

\begin{tabular}{ccr}
\hline Periode & Demand Manado (Ton) & \multicolumn{1}{c}{$\mathbf{D}^{\mathbf{2}}$} \\
\hline 1 & 450 & 202500 \\
2 & 160 & 25600 \\
3 & 750 & 562500 \\
4 & 200 & 40000 \\
5 & 350 & 122500 \\
6 & 550 & 302500 \\
7 & 175 & 30625 \\
8 & 600 & 360000 \\
9 & 250 & 62500 \\
10 & 400 & 160000 \\
11 & 200 & 40000 \\
12 & 275 & 75625 \\
\hline
\end{tabular}


Tabel 1, Tabel 2, Tabel 3, dan Tabel 4 memperlihatkan data jumlah permintaan disetiap area dan kuadrat dari permintaan, nilai total dari permintaan dan kuadrat permintaan akan digunakan untuk mencari nilai koefisien Peterson Silver, dimana apabila diketahui nilai $\mathrm{V} \geq 0,25$; maka sifat data dinamik, $\mathrm{V}<0,25$; maka sifat data statik. Persamaan Peterson Silver mengikuti Persamaan (1) berikut ini :

$$
V=\frac{n \sum_{t=1}^{\mathrm{n}} D t^{2}}{\left(\sum_{t=1}^{\mathrm{n}} D t\right)^{2}}-1
$$

Tabel 3 Nilai Koefisien Peterson Silver Data Permintaan

\begin{tabular}{cccc}
\hline No. & Nama Area & Nilai Koefisien 'V' & Sifat Data \\
\hline 1 & Makassar & 0.252102287 & Dinamik \\
2 & Manado & 0.252640771 & Dinamik \\
3 & Samarinda & 0.250128084 & Dinamik \\
4 & Banjarmasin & 0.253842125 & Dinamik \\
\hline
\end{tabular}

Perhitungan dengan metode Peterson Silver yang ditampilkan pada Tabel 3 memperlihatkan bahwa semua data permintaan adalah bersifat Dinamik, sehingga penggunaan metode Wagner Whitin dapat dilakukan. Holding Cost adalah sama pada setiap area yakni Rp 120.000/ton, sedangkan Set up Cost merupakan biaya pengiriman dan berbeda pada setiap area. 1 Kontainer dapat mengangkut 23 ton gula dan estimasi biaya antar adalah sebagai berikut: 1) MakassarMakassar:Rp 200.000/rate, 2) MakassarManado:Rp 1.200.000/rate. Set up cost juga ditentukan berdasarkan rata-rata permintaan pada sepanjang horison waktu (12 periode). Sehingga besaran Set up cost adalah sebagai berikut (dalam jutaan) : 1)MakassarMakassar:Rp 51, 2)Makassar-Manado:Rp 436.

Dari Tabel 4 dan Tabel 5 diperoleh data tentang periode pemenuhan persediaan, untuk area Makassar pemenuhan persediaan dilakukan disetiap periodenya, sehingga tidak ada persediaan untuk permintaan yang ditumpuk pada 1 periode tertentu, sedangkan pada area Manado, pemesanan persediaan dilakukan pada periode 1 dan 3 .

Tabel 4 Perhitungan Penentuan Periode Wagner Whitin (Makassar)

\begin{tabular}{|c|c|c|c|c|c|c|c|c|c|c|c|c|}
\hline Demand & 7800 & 3500 & 6500 & 2100 & 6800 & 11500 & 2200 & 7000 & 3500 & 9200 & 8500 & 2500 \\
\hline Set up Cost & 51 & 51 & 51 & 51 & 51 & 51 & 51 & 51 & 51 & 51 & 51 & 51 \\
\hline Holding Cost & 0.12 & 0.12 & 0.12 & 0.12 & 0.12 & 0.12 & 0.12 & 0.12 & 0.12 & 0.12 & 0.12 & 0.12 \\
\hline Periode & 1 & 2 & 3 & 4 & 5 & 6 & 7 & 8 & 9 & 10 & 11 & 12 \\
\hline 1 & 51 & 471 & 2031 & 2787 & 6051 & 12951 & 14535 & 20415 & 23775 & 33711 & 43911 & 47211 \\
\hline 2 & & 102 & 882 & 1386 & 3834 & 9354 & 10674 & 15714 & 18654 & 27486 & 36666 & 39666 \\
\hline 3 & & & 153 & 405 & 2037 & 6177 & 7233 & 11433 & 13953 & 21681 & 29841 & 32541 \\
\hline 4 & & & & 204 & 1020 & 3780 & 4572 & 7932 & 10032 & 16656 & 23796 & 26196 \\
\hline 5 & & & & & 255 & 1635 & 2163 & 4683 & 6363 & 11883 & 18003 & 20103 \\
\hline 6 & & & & & & 306 & 570 & 2250 & 3510 & 7926 & 13026 & 14826 \\
\hline 7 & & & & & & & 357 & 1197 & 2037 & 5349 & 9429 & 10929 \\
\hline 8 & & & & & & & & 408 & 828 & 3036 & 6096 & 7296 \\
\hline 9 & & & & & & & & & 459 & 1563 & 3603 & 4503 \\
\hline 10 & & & & & & & & & & 510 & 14046 & 15426 \\
\hline 11 & & & & & & & & & & & 561 & 10929 \\
\hline 12 & & & & & & & & & & & & 612 \\
\hline
\end{tabular}

Sumber : Pengolahan data Wagner-Whitin 
Tabel 5 Perhitungan Penentuan Periode Wagner Whitin (Manado)

\begin{tabular}{|c|c|c|c|c|c|c|c|c|c|c|c|c|}
\hline Demand & 450 & 160 & 750 & 200 & 350 & 550 & 175 & 600 & 250 & 400 & 200 & 275 \\
\hline Set up Cost & 436 & 436 & 436 & 436 & 436 & 436 & 436 & 436 & 436 & 436 & 436 & 436 \\
\hline Holding & 0.1 & & & & & & & & & & & \\
\hline Cost & 2 & 0.12 & 0.12 & 0.12 & 0.12 & 0.12 & 0.12 & 0.12 & 0.12 & 0.12 & 0.12 & 0.12 \\
\hline Periode & 1 & 2 & 3 & 4 & 5 & 6 & 7 & 8 & 9 & 10 & 11 & 12 \\
\hline 1 & 436 & $\begin{array}{c}455 . \\
2\end{array}$ & $\begin{array}{c}635 . \\
2\end{array}$ & $\begin{array}{c}707 . \\
2\end{array}$ & $\begin{array}{c}875 . \\
2\end{array}$ & $\begin{array}{c}1205 . \\
2\end{array}$ & $\begin{array}{c}1331 . \\
2\end{array}$ & $\begin{array}{c}1835 . \\
2\end{array}$ & $\begin{array}{c}2075 . \\
2\end{array}$ & $\begin{array}{c}2507 . \\
2\end{array}$ & $\begin{array}{c}2747 . \\
2\end{array}$ & $\begin{array}{c}3110 . \\
2\end{array}$ \\
\hline 2 & & 872 & 962 & 1010 & 1136 & 1400 & 1505 & 1937 & 2147 & 2531 & 2747 & 3077 \\
\hline 3 & & & 1308 & 1332 & 1416 & 1614 & 1698 & 2058 & 2238 & 2574 & 2766 & 3063 \\
\hline 4 & & & & 1744 & 1786 & 1918 & 1981 & 2269 & 2419 & 2707 & 2875 & 3139 \\
\hline 5 & & & & & 2180 & 2246 & 2288 & 2504 & 2624 & 2864 & 3008 & 3239 \\
\hline 6 & & & & & & 2616 & 2637 & 2781 & 2871 & 3063 & 3183 & 3381 \\
\hline 7 & & & & & & & 3052 & 3124 & 3184 & 3328 & 3424 & 3589 \\
\hline 8 & & & & & & & & 3488 & 3518 & 3614 & 3686 & 3818 \\
\hline 9 & & & & & & & & & 3924 & 3972 & 4020 & 4119 \\
\hline 10 & & & & & & & & & & 4360 & 3207 & 3447 \\
\hline 11 & & & & & & & & & & & 4796 & 3589 \\
\hline 12 & & & & & & & & & & & & 5232 \\
\hline
\end{tabular}

Sumber : Pengolahan data Wagner-Whitin

Tabel 6 Biaya Kumulatif Akhir Periode 12 (Makassar)

\begin{tabular}{lccccccccccccc}
\hline Periode & $\mathbf{1}$ & $\mathbf{2}$ & $\mathbf{3}$ & $\mathbf{4}$ & $\mathbf{5}$ & $\mathbf{6}$ & $\mathbf{7}$ & $\mathbf{8}$ & $\mathbf{9}$ & $\mathbf{1 0}$ & $\mathbf{1 1}$ & $\mathbf{1 2}$ \\
\hline Permintaan & 7800 & 3500 & 6500 & 2100 & 6800 & 11500 & 2200 & 7000 & 3500 & 9200 & 8500 & 2500 \\
Penerimaan & 7800 & 3500 & 6500 & 2100 & 6800 & 11500 & 2200 & 7000 & 3500 & 9200 & 8500 & 2500 & 0 \\
Persediaan & 0 & 0 & 0 & 0 & 0 & 0 & 0 & 0 & 0 & 0 \\
\hline Biaya Kumulatif & 397800 & 576300 & 907800 & 1014900 & 1361700 & 1948200 & 2060400 & 2417400 & 2595900 & 3065100 & 3498600 & $\mathbf{3 6 2 6 1 0 0}$ \\
\hline
\end{tabular}

Sumber : Pengolahan data Biaya Kumulatif

Tabel 7 Biaya Kumulatif Akhir Periode 12 (Manado)

\begin{tabular}{lcccccccccccccc} 
Periode & $\mathbf{1}$ & $\mathbf{2}$ & $\mathbf{3}$ & $\mathbf{4}$ & $\mathbf{5}$ & $\mathbf{6}$ & $\mathbf{7}$ & $\mathbf{8}$ & $\mathbf{9}$ & $\mathbf{1 0}$ & $\mathbf{1 1}$ & $\mathbf{1 2}$ \\
\hline Permintaan & 450 & 160 & 750 & 200 & 350 & 550 & 175 & 600 & 250 & 400 & 200 & 275 \\
Penerimaan & 610 & 0 & 3750 & 0 & 0 & 0 & 0 & 0 & 0 & 0 & 0 & 0 & \\
Persediaan & 160 & 0 & 3000 & 2800 & 2450 & 1900 & 1725 & 1125 & 875 & 475 & 275 & 0 \\
\hline $\begin{array}{l}\text { Biaya } \\
\text { Kumulatif }\end{array}$ & 265979.2 & 265979.2 & 1901339 & 1901675 & 1901969 & 1902197 & 1902404 & 1902539 & 1902644 & 1902701 & 1902734 & $\mathbf{1 9 0 2 7 3 4}$ \\
\hline
\end{tabular}

Sumber : Pengolahan data Biaya Kumulatif

Tabel 6 dan Tabel 7 memperlihatkan jumlah biaya pada akhir periode 12, bila perusahaan menggunakan metode WagnerWhitin dalam menentukan periode dan nilai persediaan yang harus disediakan dalam mengantisipasi datangnya permintaan, maka akan diperoleh biaya kumulatif dari persediaan (holding cost) dan penerimaan (set up cost). Besaran biaya akumulatif adalah dalam satuan jutaan, hal yang kontradiktif disini adalah besarnya biaya untuk area Manado (Rp 1.902.734) pada akhir periode ternyata lebih minimum dibandingkan dengan Makassar (Rp 3.626.100).

\section{KESIMPULAN}

Kesimpulan dari penelitian adalah, dengan menggunakan metode WagnerWhitin, diperoleh periode yang tepat untuk 
pemenuhan persediaan area Makassar adalah pada setiap periode (1-12), sedangkan untuk area Manado adalah pada periode 1 dan periode 3. Meskipun jarak antara pabrik dan gudang sangat dekat untuk area Makassar, tetapi biaya pemenuhan persediaan pada akhir periode lebih mahal dibanding Manado, hal ini terjadi akibat efek dari biaya set up yang terjadi sepanjang periode, dan dapat pula disimpulkan bahwa ada kemungkinan perusahaan akan dapat lebih meminimumkan biaya dengan melakukan penumpukkan persediaan pada 1 atau awal periode untuk men-cover permintaan pada seluruh periode, hal ini terjadi karena biaya simpan (holding cost) ternyata bukanlah suatu variabel yang signifikan berpengaruh pada biaya, selain itu jumlah permintaan yang memang lebih besar menjadi penyebab tingginya biaya di area Makassar.

\section{DAFTAR PUSTAKA}

1. Axsater, Sven, 2002, Inventory Control, Second Edition. Springer Publication Inc.

2. Gokhan Baltacioglu, Izzettin Temiz, Serpil Erol, 2011, "Fuzzy Wagner Whitin Algorithm and an Application of Class I Supplies", Gazi University Journal of Science, vol. 24, no. 1, pp. 125-134.

3. Sipper, D. \& Robert L. Bulfin, 1997, Production Planning, Control and Integration. United State : McGrawHill.

4. Standard Nasional Indonesia, 2006, Gula kristal-Bagian 2: Rafinasi (refined sugar). Badan Standardisasi Nasional.

5. S.J.Sadjadi, Mir.B.Gh. Aryanezhad, H.A.Sadeghi, 2009, "An Improved Wagner-Whitin Algorithm", International Journal of Industrial Engineering and Production Research, vol. 20, no. 3, pp. 117-123.

6. http://jaringnews.com/ekonomi/umum/9 490/mendag-tekankan-ubah-polakonsumsi- untuk-capai-ketahananpangan 